\title{
Intranasal application of glucocorticoid alleviates olfactory dysfunction in mice with allergic rhinitis
}

\author{
XIAOWEI WANG, YINGYING ZHU, DAOFENG NI, WEI LV, ZHIQIANG GAO and FANG QI \\ Department of Otolaryngology, Peking Union Medical College Hospital, \\ Chinese Academy of Medical Sciences and Peking Union Medical College, Beijing 100730, P.R. China
}

Received December 12, 2015; Accepted March 6, 2017

DOI: $10.3892 / \mathrm{etm} .2017 .5042$

\begin{abstract}
The aim of the present study was to investigate the effect of glucocorticoid intervention on olfactory dysfunction in mice with allergic rhinitis (AR). An AR animal model was established by intraperitoneal injection and intranasal application of ovalbumin to mice. The olfactory function of the mice was evaluated using a buried food test, and morphological changes in the nasal mucosa were determined using hematoxylin and eosin staining. The expression of olfactory marker protein (OMP) in the olfactory mucosa was tested by immunohistochemistry, and was observed on days 7 and 14 after the application of glucocorticoid. The incidence rate of olfactory dysfunction in AR mice was $75.34 \%$, and the olfactory epithelium became thinner in mice with AR compared to the control group. In addition, the expression of OMP in the olfactory epithelium was downregulated in mice with AR compared with the control group. Expression of OMP in the olfactory epithelium was upregulated in the budesonide group A and betamethasone group A compared with the medicine-free group, whereas the expression of OMP in the olfactory epithelium of budesonide group A or betamethasone group A was not significantly different from the control group. Moreover, the expression of OMP in the budesonide group B was similar to budesonide group A, and expression of OMP in betamethasone group B was similar to betamethasone group A. The expression of OMP in olfactory mucosa is downregulated in AR mice with olfactory dysfunction. Following the application of glucocorticoid, the expression of OMP in the olfactory mucosa in mice is upregulated. Moreover, intranasal local glucocorticoid has a low incidence of systemic adverse reactions, and is recommended for the treatment of olfactory dysfunction in AR.
\end{abstract}

Correspondence to: Professor Fang Qi, Department of Otolaryngology, Peking Union Medical College Hospital, Chinese Academy of Medical Sciences and Peking Union Medical College, 1 Shuaifuyuan Street, Beijing 100730, P.R. China

E-mail: 495065986@qq.com

Key words: allergic rhinitis, olfactory dysfunction, glucocorticoid

\section{Introduction}

Olfaction is an important function of the body. The main functions of olfaction include odor discrimination, environmental identification, appetite stimulation and emotional regulation. Olfactory disorder is very common and a study on the function of smell in 1.5 million people reports that $1.2 \%$ people have a permanent loss and $62.4 \%$ have a temporary loss of the sense of smell (1). Common causes of olfactory dysfunction include infection of the upper respiratory tract, nasal sinus disease, nasal operation, brain and nasal tumors, endocrine disorders, head injury, age, radiation, toxic chemicals, mental, drug and congenital factors and neurodegenerative diseases amongst other causes (2).

Allergic rhinitis (AR) is the most common otorhinolaryngological disease (3). It is also one of the main causes of olfactory dysfunction (4). The primary clinical manifestations of AR include nasal blockage, running and itching nose, sneezing, olfactory dysfunction amongst others (3). Moreover, the incidence rate of AR is increasing each year $(5,6)$. AR is currently a primary factor of olfactory dysfunction $(7,8)$; however, current epidemiological investigations suggest that the incidence of AR is $10-30 \%$ of the human population (9). It has also been reported that the loss or impairment of olfaction is associated with nasal allergy reactions (10). A survey by Cowart et al (11) reported that $23.1 \%$ of patients with AR have an impaired sense of smell, whereas, Rombaux et al (12) report that the incidence of smell disorder caused by AR is 15-20\%. However, the mechanism by which AR induces olfactory dysfunction remains unclear. It is considered that nasal inflammation that blocks the passage for odor molecules to reach olfactory receptors on the top of the nasal cavity is the main reason that leads to olfactory dysfunction, namely conductive olfactory dysfunction. However, recent studies have demonstrated that pathological changes in olfactory epithelium tissues caused by allergy, namely sensory olfactory disorder, may be one of the direct causes of olfactory dysfunction in AR patients (4,13-15).

Olfactory receptor neurons (ORNs) are the receptor cells responsible for the olfactory sense. During breathing, odor molecules arrive at the ORNs in the olfactory epithelium, cause depolarization of the receptor cells and generate action potentials $(16,17)$. The action potentials are applied along the axon to the olfactory bulb, then transferred onto the olfactory 
center, resulting in the sense of smell $(16,17)$. Olfactory marker protein (OMP) is a type of protein of limited solubility that is expressed in mature ORNs, and is considered to be a sign for maturation of ORNs $(18,19)$.

To date there has been no ideal treatment for olfactory disorders induced by AR or other causes. In clinical practice, glucocorticoid is often used for the treatment of olfactory dysfunction. For example, the study by Faulcon et al (20) indicated a good therapeutic effect of glucocorticoid on 41 patients with olfactory dysfunction. Moreover, the clinical study performed by Heilmann et al (21) on 55 patients with olfactory dysfunction demonstrates that oral administration of prednisolone improves smell dysfunction caused by upper respiratory tract infection, sinusitis, idiopathic anosmia amongst other various reasons. Stevens (22) observed that patients with nasal polyps still have olfactory dysfunction following endoscopic sinus surgery performed to relieve obstruction, and daily administration of $40 \mathrm{mg}$ oral prednisone (tapered) contributes to an improvement in olfaction. In addition, local aerodynamic inhalation of glucocorticoid has achieved good clinical results in the treatment of olfactory dysfunction $(23,24)$. However, there have been few clinical studies performed on the effect of glucocorticoid in the treatment of olfactory disorder caused by AR. In the present study, OMP changes in the olfactory epithelium of mice are investigated.

\section{Materials and methods}

Animals and grouping. A total of $90 \mathrm{BALB} / \mathrm{C}$ mice of clean grade (male, 8 weeks old with a body weight of $25 \pm 1 \mathrm{~g}$ ) were used in the present study (Experimental Animal Center of Peking Union Medical College Hospital, Chinese Academy of Medical Sciences, Beijing, China). The mice were randomly divided into an AR model (80 mice) and control (10 mice) groups. For sensitization, the AR model group of mice were intraperitoneally injected with ovalbumin $\mathrm{Al}(\mathrm{OH})_{3}$ solution $(300 \mu \mathrm{g} / \mathrm{kg}$ body weight; Sigma-Aldrich; Merck KGaA, Darmstadt, Germany) once every other day and 7 times in total. Instead, ovalbumin solution was substituted with saline for the control group. For excitation, the mice were anesthetized with an intraperitoneal injection of $50 \mathrm{mg} / \mathrm{kg} 1 \%$ pentobarbital (Gene Company Ltd., Hong Kong, China) on day 7 after the end of sensitization. Next, ovalbumin solution ( $80 \mu \mathrm{g} / \mathrm{kg}$ body weight) was slowly and steadily dripped into the bilateral anterior nostrils of mice, and into the nasal cavity by breathing. Excitation was performed one time a day for a consecutive 7 days. For the control group, ovalbumin solution was replaced by saline. Moreover, the symptom behavior superposition score method was used to evaluate the model (25). In total, $30 \mathrm{~min}$ after the last nasal excitation and secretion, sneezing frequency and the nose-scratching times were observed and recorded. According to the superposition quantization scoring (Table I), successful modeling was defined if the total score was $>5$ points. All animal experiments were conducted according to the ethical guidelines of Peking Union Medical College Hospital.

Animal model. In order to examine olfactory disorders, the buried food test (BFT) was performed. Food pellets were randomly buried in the litter at depths of $1-2 \mathrm{~cm}$. Next, the mice were placed into the location of the experiment and mice
Table I. Superposition quantization scoring.

\begin{tabular}{lccc}
\hline Score & $\begin{array}{c}\text { Nose } \\
\text { scratching }\end{array}$ & Discharging & Sneezing \\
\hline 0 & Never & None & Never \\
1 & Occasionally & Reaching the anterior nostril & $1-3$ \\
2 & Frequently & Over the anterior nostril & $4-10$ \\
3 & Cannot stop & Flowing all the face & $>10$ \\
\hline
\end{tabular}

that were unable to find food pellets within $300 \mathrm{sec}$ (5 times on average) were defined to have olfactory dysfunction. According to this standard, the AR model group of mice was divided into a group with olfactory dysfunction (55 mice) and a group without dysfunction (25 mice). The mice in the control group were also assessed by BFT, and their results were compared with those of the AR model group.

On day 3 after successful modeling, 9 mice in the group with olfactory dysfunction and 9 mice in the group without dysfunction were randomly selected. Moreover, all mice in the control group were selected ( 8 mice as 2 mice died). The mice were anesthetized with an intraperitoneal injection of pentobarbital (1\% pentobarbital $50 \mathrm{mg} / \mathrm{kg}$; Gene Company Ltd.) and then sacrificed by breaking marrow, removing the head fur and exposing the skulls. For further treatment of pruning skull specimens, the upper part of the nasal cavity was retained, including the nasal septum and lateral wall as well as the ethmoid plate. The samples were then kept in $4 \%$ polyformaldehyde solution (Beijing Dingguo Biotechnology Co., Ltd., Beijing, China) for $48 \mathrm{~h}$, and soaked in 10\% EDTA solution (Beijing Sequoia Jinqiao Biological Technology Co., Ltd., Beijing, China) for 14 days, with daily replacement of decalcifying fluid. Following decalcification, the specimens were rinsed with tap water for $24 \mathrm{~h}$ before being fixed in $4 \%$ polyformaldehyde solution again for $24 \mathrm{~h}$.

Medicine intervention was initiated on day 3 after successful modeling. The remaining 46 mice in the group with olfactory dysfunction were randomly divided into the following 5 groups: Budesonide group A $(n=9)$, budesonide group B $(n=10)$, betamethasone group A $(n=9)$, betamethasone group $B(n=9)$ and medicine-free group $(n=9)$. The mice in the budesonide groups A and B received nasal drips of $30 \mu \mathrm{l}$ budesonide (Rhinocort; AstraZeneca PLC, London, UK) into each nasal cavity once a day for consecutive 5 days. The mice in the betamethasone groups A and B were treated with an intraperitoneal injection of $100 \mu 1(3.5 \mathrm{mg} / \mathrm{kg})$ betamethasone solution (Shanghai Schering-Plough Pharmaceutical Co., Ltd., Shanghai, China) once, and the mice in the medicine-free group did not receive any medical intervention. On day 7 after the start of intervention, the mice in the budesonide group A, betamethasone group A and medicine-free group were sacrificed to collect tissues. On day 14 after the start of intervention, the mice in the budesonide group B and betamethasone group B were also sacrificed to collect tissues.

Hematoxylin and eosin (H\&E) staining. In total 3 samples were randomly selected from the control group, AR model group without olfactory dysfunction and AR model group 
with olfactory dysfunction for gradient ethanol dehydration, paraffin embedding and serial sections into 4-5 $\mu \mathrm{m}$. For conventional smear preparations, conventional smear glass slides were fixed with $95 \%$ ethanol for at least $15 \mathrm{~min}$, and then treated with water for $1 \mathrm{~min}$, hematoxylin for $10 \mathrm{~min}$, running water for $15 \mathrm{~min}$, eosin for $30 \mathrm{sec}$, $95 \%$ ethanol for $1 \mathrm{~min}$ and $100 \%$ ethanol for $2 \mathrm{~min}$. Stained slides were cover-slipped with permount. Finally, the entire H\&E-stained cells were examined under a light microscope using magnification of x 200-400

Immunohistochemistry. A total of 3 samples were randomly selected from each group. The samples were heated at $60^{\circ} \mathrm{C}$ for $1-2 \mathrm{~h}$, dewaxed at $60^{\circ} \mathrm{C}$ for $10 \mathrm{~min}$ and dehydrated with ethanol for $2 \mathrm{~min}$. The sections were then washed with distilled water for $3 \mathrm{~min}$, and soaked in $3 \%$ hydrogen peroxide methanol solution at room temperature for $10 \mathrm{~min}$. Next, the sections were rinsed with $0.01 \mathrm{~mol} / \mathrm{l}$ phosphate-buffered saline (PBS) 3 times for 5 min each time. The sections were then incubated with the primary antibody $(1: 8,000$; goat anti-human OMP monoclonal antibody; Wako Pure Chemical Industries, Ltd., Osaka, Japan) overnight at $4{ }^{\circ} \mathrm{C}$, followed by rinsing with $0.01 \mathrm{~mol} / 1$ PBS 3 times for 5 min each time. Thereafter, the sections were incubated with horseradish peroxidase-labeled rabbit anti-goat antibody (PV-6003; Beijing Sequoia Jinqiao Biological Technology Co., Ltd., Beijing, China) at $37^{\circ} \mathrm{C}$ in a humidified box for 30-60 min, followed by rinsing with $0.01 \mathrm{~mol} / \mathrm{l}$ PBS 3 times for $5 \mathrm{~min}$ each time. The sections were stained with 3,3'-diaminobenzidine, counterstained with hematoxylin, dehydrated in graded ethanol and made transparent using xylene and sealed. Finally, the sections were observed under an optical microscope (magnification, $x 400$ ), and all OMP-positive cells were analyzed.

Statistical analysis. All the results were analyzed using SPSS 11.0 statistical analysis software (SPSS, Inc., Chicago, IL, USA). Each group of data was compared using the paired t-test and numeral materials were expressed as the mean \pm standard deviation. $\mathrm{P}<0.05$ was used to indicate a statistically significant difference.

\section{Results}

Establishment of the model of AR mice is successful. In order to evaluate the establishment of models, the symptom behavior superposition scoring method was adopted. Following excitation, 7 mice in the AR model group and 2 mice in the control group died. The mice that survived in both groups had a shiny fur color, normal eating and drinking behavior, a sensitive reaction and normal activities. Compared with the control group, the mice in the AR model group demonstrated clear secretions in the snout, and the number of times of nose-scratching occurred was increased. Moreover, there was no significant difference in body weight between the AR model $(25.38 \pm 0.52 \mathrm{~g})$ and control $(25.52 \pm 0.70 \mathrm{~g})$ groups $(\mathrm{P}>0.05)$. It was demonstrated that mice in the AR model group were frequently scratching their nose using fingernails, and they revealed an onset of sneezing, with nasal secretions flowing out of the nose to form two wet marks of clear liquid around the snout. However, no evident symptoms in the control
Table II. Symptoms of mice in the AR model group.

\begin{tabular}{lccc}
\hline Score & $\begin{array}{c}\text { Nose scratching } \\
\text { (mice) }\end{array}$ & $\begin{array}{c}\text { Discharging } \\
\text { (mice) }\end{array}$ & $\begin{array}{c}\text { Sneezing } \\
\text { (mice) }\end{array}$ \\
\hline 0 & 0 & 0 & 0 \\
1 & 4 & 17 & 14 \\
2 & 36 & 46 & 21 \\
3 & 33 & 10 & 38 \\
\hline
\end{tabular}

AR, allergic rhinitis.

group of mice were observed ( 0 point). In addition, there was a significant difference between the two groups $(\mathrm{P}<0.01$; Table II). The results suggested that the establishment of the model of AR mice was successful.

Mice in the group with olfactory dysfunction account for $75.34 \%$ of the total number of mice in the AR model group. To determine the olfactory function of mice, BFT was performed. The data demonstrated that all of the 8 mice in the control group could find buried food pellets within $300 \mathrm{sec}$ (average time, $126 \pm 5 \mathrm{sec})$. In addition, 18 mice in the AR model group could find food pellets within $300 \mathrm{sec}$ (average time, $144 \pm 7 \mathrm{sec}$ ), and were classified into groups without olfactory dysfunction. The remaining 55 mice in the AR model group could not find buried food pellets in $300 \mathrm{sec}$, and were classified into the group with olfactory dysfunction. The results indicate that mice in the group with olfactory dysfunction account for $75.34 \%$ of the total number of mice in the AR model group.

$A R$ induces morphological changes in the nasal mucosa even if olfactory dysfunction occurs. In order to observe morphological changes in the nasal mucosa, H\&E staining was used. Mouse olfactory mucosa was located on the roof of the bilateral nasal cavity, inferior to the middle part of the nasal septum and bilateral lateral wall, and composed of epithelium and lamina propria (Fig. 1A). H\&E staining revealed that the olfactory mucosa epithelial layer in the control group contained ORNs, supporting cells (SCs) and basal cells (BCs). Moreover, ORNs were located in the middle part of the olfactory epithelium, with 7 or 8 layers, and with round, dark blue nuclei. SCs were located near the surface of the olfactory epithelium, with elliptical and light blue nuclei. BCs were located on the bottom of the olfactory epithelium, close to the basement membrane, and with small and oblate nuclei. Moreover, the lamina propria contained olfactory nerves and blood vessels (Fig. 1B). Each layer of epithelial cells was arranged in neat rows, and with an apparent polarity and the epithelium became thinner in mice in either group (with or without olfactory dysfunction). Furthermore, the layers of ORNs were reduced and arranged in disorder. In addition, there was no evident morphological difference between the two groups, but the morphology of the nasal mucosa in the AR model group was different from that of the control group (Fig. 2). These results indicate that AR induces morphological changes in the nasal mucosa even if olfactory dysfunction occurs. 
A

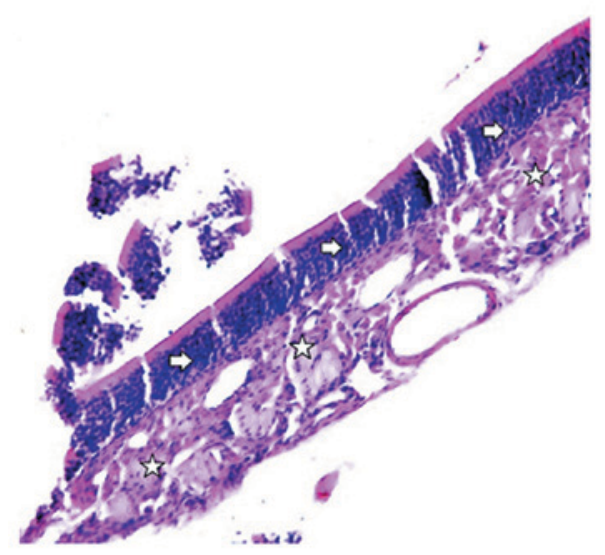

B

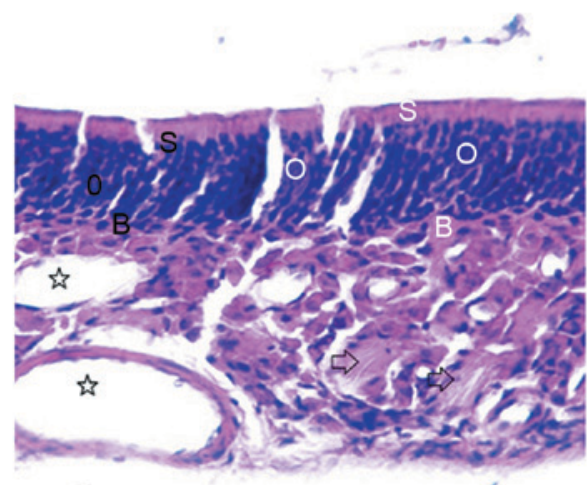

Figure 1. Olfactory mucosa in the control group. Hematoxylin and eosin staining was performed. (A) Epithelium and lamina propria (magnification, x100). Arrows indicate the epithelium, while stars depict the lamina propria. (B) Olfactory mucosa epithelial layer containing ORNs, supporting and basal cells (magnification, x200). 'O' indicates ORNs, 'S' indicates supporting cells, 'B' indicates basal cells, arrows indicate blood vessels and stars indicate nerve fibers. ORNs, olfactory receptor neurons.

A

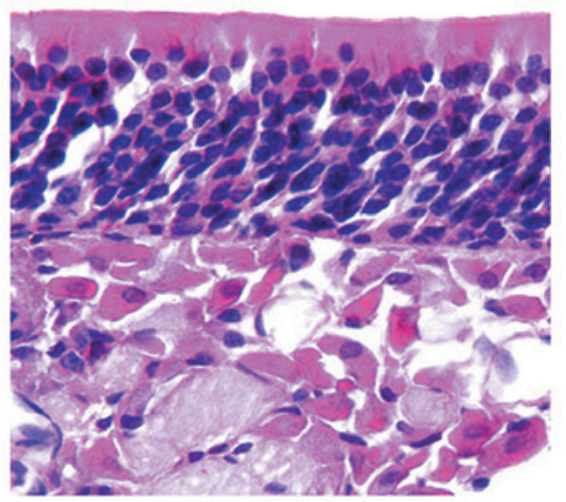

B

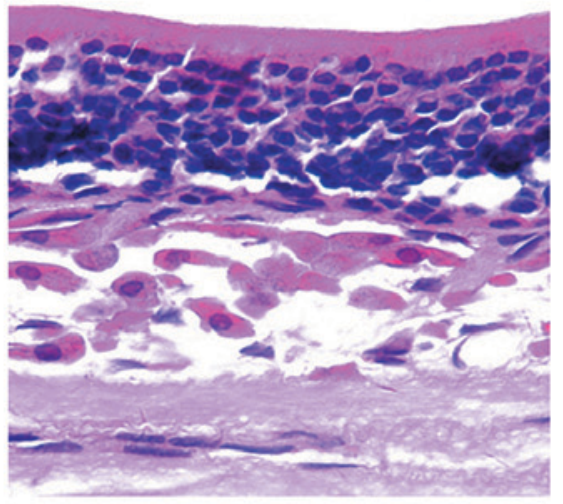

C

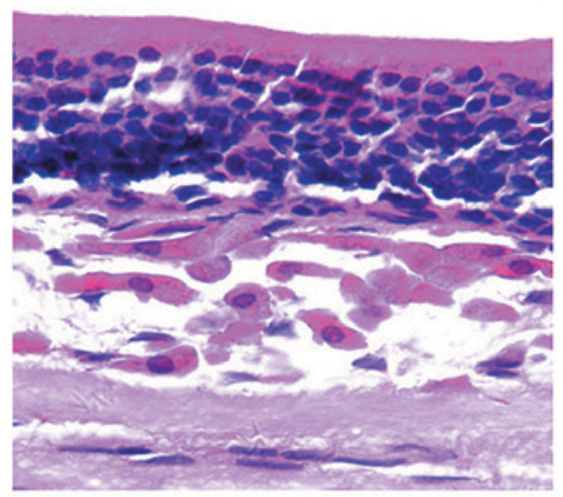

Figure 2. Olfactory mucosa in mice in (A) the control, (B) group without olfactory dysfunction and (C) group with olfactory dysfunction. Hematoxylin and eosin staining was performed (magnification, $\mathrm{x} 400$ ).

Treatment with budesonide or betamethasone restores a reduced number of OMP-positive cells in AR mice with olfactory dysfunction to levels similar to that in healthy mice. In order to observe histological changes in the nasal mucosa, immunohistochemistry was performed. OMP-positive cells in the control group were stained brown under an optical microscope and were then distributed in the olfactory mucosal epithelium and lamina propria. In addition, the OMP reaction was also observed in the olfactory mucosal surface cilia (Fig. 3). A large number of OMP-positive cells were observed in the epithelial layer of the olfactory mucosa.

In the lamina propria, brown olfactory nerve fibers were observed in the network, while no OMP-positive reaction was observed in the vascular wall (Fig. 4A). The number of OMP-positive cells in the control group was $66.38 \pm 1.52$ (Table III). Moreover, in the group without olfactory dysfunction, the olfactory mucosa epithelial layer was thin and pale under a microscope, with the expression of OMP being lower than that in the control group. The number of OMP-positive cells in the group without olfactory dysfunction was $59.50 \pm 0.56$, which was not significantly different to the control $(\mathrm{P}>0.05$; Fig. 4B and Table III). Similarly, in the group with olfactory

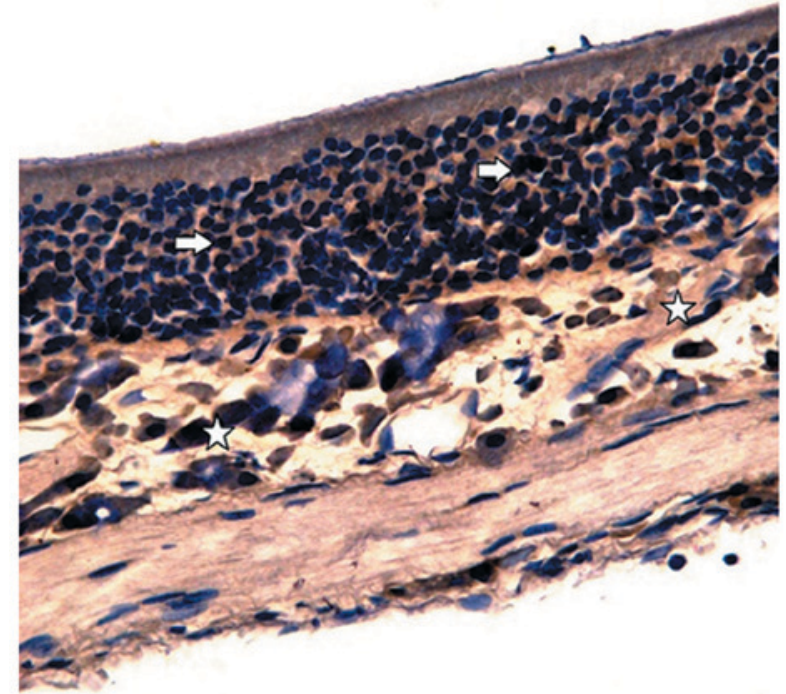

Figure 3. Expression of OMP in olfactory mucosa in healthy mice. OMP immunoreactive cells were stained brown by immunohistochemical staining (magnification, x200). Arrows indicate epithelium, while stars indicate lamina propria. OMP, olfactory marker protein. 
A

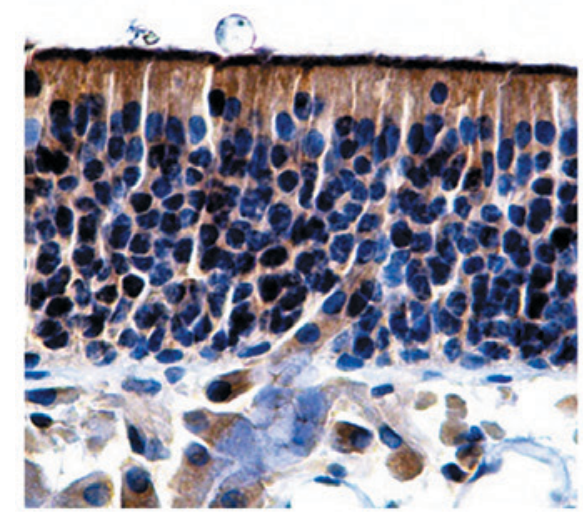

B

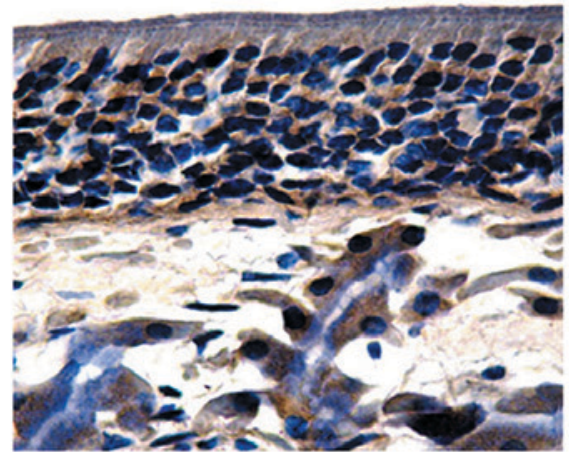

C

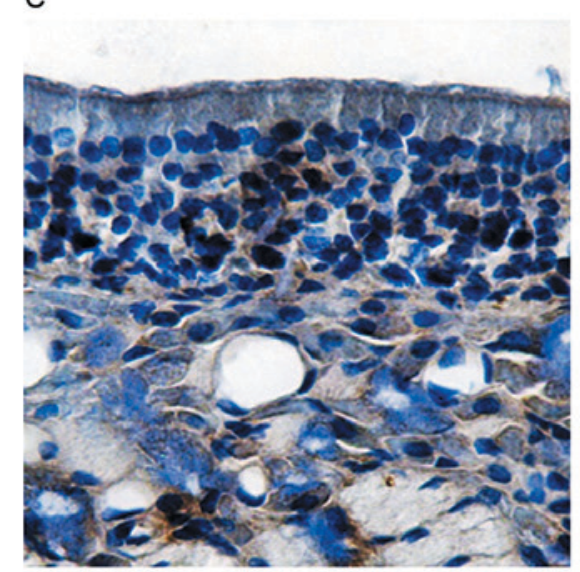

Figure 4. Expression of OMP in olfactory mucosa in (A) the control, (B) group without olfactory dysfunction and (C) group with olfactory dysfunction. OMP immunoreactive cells were stained brown by immunohistochemical staining (magnification, $\mathrm{x} 400$ ). OMP, olfactory marker protein.

dysfunction, the olfactory epithelium layer was also thin and pale, and the expression of OMP was significantly lower than the control, with no positive brown staining in the cilia of the surface layer. The number of OMP-positive cells in the group with olfactory dysfunction was $39.77 \pm 2.01$, which was significantly different from those in the control group and the group without olfactory dysfunction $(\mathrm{P}<0.05$; Fig. 4C and Table III).

In the budesonide group $\mathrm{A}$, the olfactory mucosa epithelial layer was thickened, the expression of OMP was increased and the number of OMP-positive cells $(61.51 \pm 1.62)$ was significantly higher compared with the group with olfactory dysfunction $(\mathrm{P}<0.05)$. However, no significant differences were observed between the budesonide group A and control group ( $\mathrm{P}>0.05$; Fig. $5 \mathrm{~A}$ and Table III). In the betamethasone group A, the olfactory mucosa epithelial layer was thickened, the expression of OMP was increased and the number of OMP-positive cells $(62.04 \pm 1.23)$ was significantly higher compared with the group with olfactory dysfunction $(\mathrm{P}<0.05)$. However, no significant differences were observed between the betamethasone group A, control or budesonide group A ( $P>0.05$; Fig. 5B and Table III). In the medicine-free group, the thickness of the olfactory epithelial layer was increased and cell arrangement was disordered. Moreover, the expression of OMP was increased slightly, and the number OMP-positive cells $(47.34 \pm 1.81)$ was not significantly different from the group with olfactory dysfunction $(\mathrm{P}>0.05)$, but was significantly less than the number of OMP-positive cells in either the budesonide group $\mathrm{A}$ or betamethasone group $\mathrm{A}(\mathrm{P}<0.05$; Fig. $5 \mathrm{C}$ and Table III). Finally, in the budesonide group B, the expression of OMP was similar to that of the budesonide group A. Moreover, the number of OMP-positive cells $(60.19 \pm 1.32)$ was slightly less than the budesonide group A ( $>>0.05$; Fig. 6A and Table III). In the betamethasone group $\mathrm{B}$, the expression of OMP was similar to the betamethasone group A, and the number of OMP-positive cells $(63.82 \pm 1.254)$ was not significantly different from the betamethasone group $\mathrm{A}(\mathrm{P}>0.05)$ or budesonide group B ( $\mathrm{P}>0.05$; Fig. $6 \mathrm{~B}$ and Table III). These results indicate that treatment with budesonide or betamethasone restores a reduced number of OMP-positive cells in AR mice with olfactory dysfunction to levels similar to that in healthy mice.
Table III. Number of OMP-positive cells in each group.

Groups

OMP-positive cells (n)

Control

$66.38 \pm 1.52$

Group without olfactory dysfunction

$59.50 \pm 0.56$

Group with olfactory dysfunction

$39.77 \pm 2.01^{\mathrm{a}}$

Budesonide group A

Betamethasone group A

$61.51 \pm 1.62^{\mathrm{b}}$

Medicine-free

$62.04 \pm 1.23$

Budesonide group B

Betamethasone group B

$47.34 \pm 1.81^{\mathrm{c}}$

$60.19 \pm 1.32$

$63.82 \pm 1.26$

${ }^{a} \mathrm{P}<0.05$ vs. control group or the group without olfactory dysfunction; ${ }^{\mathrm{b}} \mathrm{P}<0.05$ vs. group with olfactory dysfunction; ${ }^{\mathrm{C}} \mathrm{P}<0.05$ vs. budesonide group A or betamethasone group A. OMP, olfactory marker protein.

\section{Discussion}

The establishment of an animal model is an effective means of studying the pathogenesis and pathophysiological basis of diseases. The principle of establishing a model is to reliably and specifically reflect the clinical features and pathological changes, with good repeatability. Toluene diisocyanate (TDI) and OVA are mainly used as allergens in the establishment of AR animal models (26-28). Since TDI has a stimulation effect on mucosa and inflammatory injury, it cannot be widely used. By contrast, OVA is more widely used because its stimulation effect is small and sensitization is better $(29,30)$. When selecting animal models, mice have congenital favorable factors for allergic diseases, including mild temperament, low aggressivity, short growth period, high fecundity, a developed lymph system and sensitivity to outside stimuli. In addition, the mouse gene map has nearly been completed, resulting in a deeper understanding of the immune system of mice. Therefore, BALB/C mice were selected as model animals in the present study. Moreover, OVA and adjuvant $\mathrm{Al}(\mathrm{OH})_{3}$ were used to sensitize animal bodies and to maintain nasal excitation. This model provides the basis for the study of OMP 

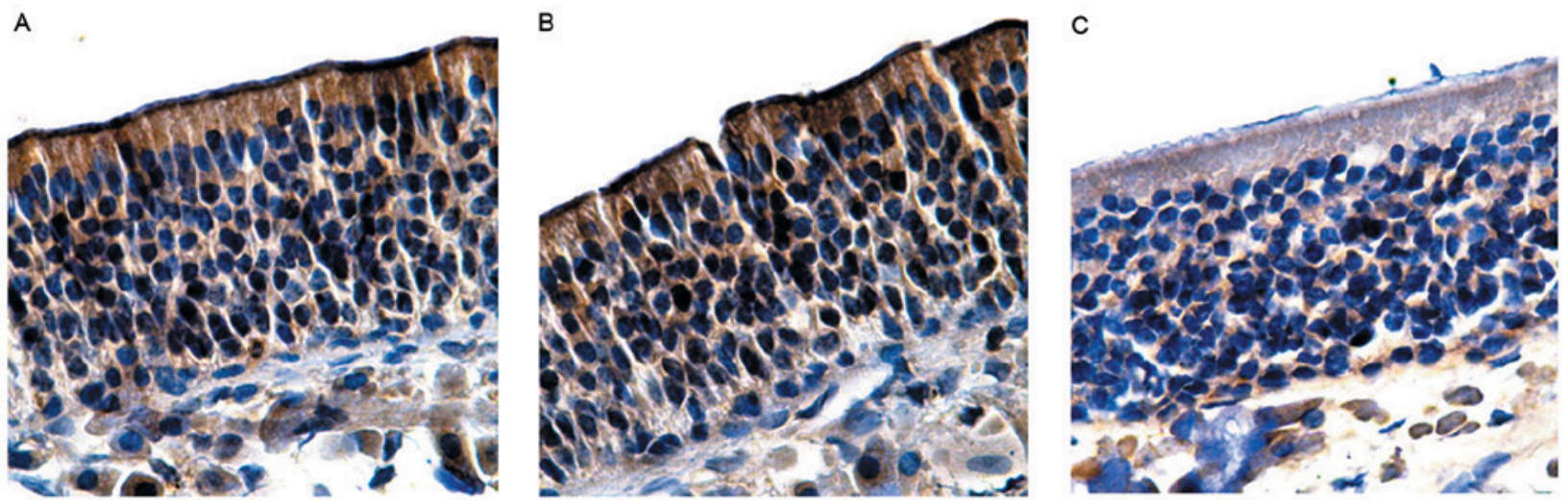

Figure 5. Expression of OMP of olfactory mucosa 1 week after medical intervention. (A) Budesonide group A, (B) betamethasone group A and (C) medicine-free group. OMP immunoreactive cells were stained brown by immunohistochemical staining (magnification, $\mathrm{x} 400$ ). OMP, olfactory marker protein.
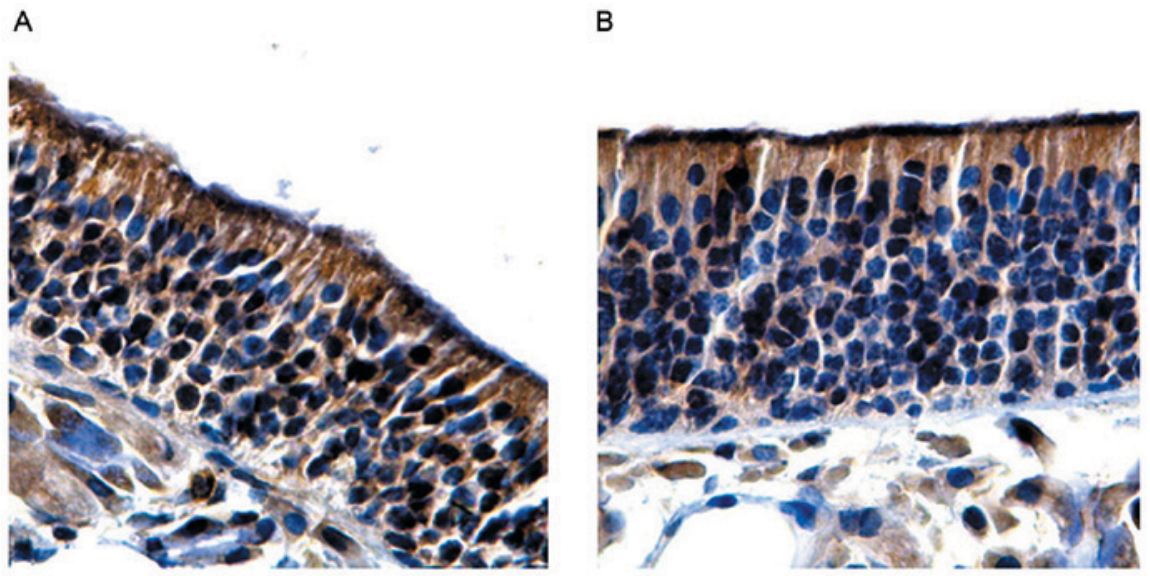

Figure 6. Expression of OMP of olfactory mucosa 2 weeks after medical intervention. (A) Budesonide group B and (B) betamethasone group B. OMP immunoreactive cells were stained brown by immunohistochemical staining (magnification, x400). OMP, olfactory marker protein.

expression in the olfactory epithelium in AR and the effect of glucocorticoid invention.

Evaluation of the olfactory function trough behavioral changes is currently a widely used experimental method $(31,32)$. BFT is the olfactory evaluation method that has been applied to evaluate mouse olfactory disorder behavior, and this method has also improved $(33,34)$, and it is easy to operate with a low cost, good feasibility and reproducibility. The present study performed preliminary assessment with BFT on all mice before grouping, and all mice could find food pellets within $300 \mathrm{sec}$, demonstrating that $300 \mathrm{sec}$ is and feasible as a grouping criterion in olfactory behavioral experiments. In total, $\sim 74.55 \%$ of AR model mice demonstrated olfactory dysfunction in the present study, and the results confirm that olfactory dysfunction is a common symptom of AR.

The mechanism by which AR causes olfactory dysfunction is not entirely clear yet. It is thought that the loss of smell is conductive, due to the blocked channels for odor molecules to reach to the top of the nasal cavity olfactory receptor, and the intact olfactory epithelium (35). Recent studies tend to think that the degree of nasal obstruction is not directly associated with olfactory dysfunction caused by AR $(4,36)$. Moreover, the use of epinephrine nasal decongestants cannot return the olfactory function of AR patients to normal (37). The study by Cowart et al (11) also demonstrated that even if the lower passage of the nasal cavity is completely blocked, it is still not enough to cause a significant decrease in the olfactory sensitivity. This indicates that pathological changes of the olfactory epithelium itself may be the main reason for olfactory dysfunction caused by AR. In the present study, the olfactory epithelium of AR model mice is thinner, the layer of cells is arranged in irregular order, the plies of cells are significantly reduced and the polarity is lost. The results show that the olfactory mucosa has evident pathological changes and that the ORNs have pathological injury.

In the studies related to olfactory sense, OMP has recently attracted a lot of attention. OMP is a type of protein closely associated with the sense of smell, and it is specifically expressed in mature ORNs. Moreover, ORNs are the only neurons in the olfactory mucosa. Their function is to sense odor molecules in the air, to change chemical signals into electrical signals and to transmit olfactory information to olfactory bulb and olfactory senior center $(16,17,38)$. The results in the present study demonstrated that expression of OMP in the AR model group was lower than the control group, and the OMP expression level in the group with olfactory dysfunction was significantly lower than that in the control. This indicates that the olfactory mucosa has pathological changes.

There is no ideal and standard treatment for olfactory dysfunction to date. However, previous results demonstrate a 
method to enhance olfactory sensitivity by short-term systemic contact with multiple specific odors (39), and attempts have been made to improve the olfactory sensitivity by repeated magnetic stimulation of the frontal cortex (40). However, these new efforts have not been clinically applied yet. The treatment for olfactory dysfunction at present still uses corticosteroids as a first choice. There are numerous reports on glucocorticoid treatment for olfactory dysfunction. Hotchkiss (41) reported that oral glucocorticoid improves olfactory dysfunction induced by nasal polyps. Moreover, Fukazawa et al (42) gave nasal septum mucosal local injection of dexamethasone to 102 patients with a different etiology of olfactory disorder, and $63.7 \%$ patients demonstrated an improved sense of smell. Finally, Guan et al (24) used intranasal pneumatic jet atomization inhalation of budesonide suspension for the treatment of patients with olfactory dysfunction with different causes, and achieved better therapeutic effects. Furthermore, other studies revealed that glucocorticoid combined with extracts of Ginkgo biloba may have an improved treatment effect $(43,44)$.

The mechanism of action of glucocorticoid in the treatment for olfactory dysfunction is not fully understood yet. It is known that glucocorticoid improves the sense of smell by inhibiting inflammatory cytokine production, induces the anti-inflammatory factor to reduce the inflammation of olfactory mucosa, alleviates the congestion and edema to increase the contact area of olfactory mucosa with odor molecules in the air and promotes odor molecules to combine with ORNs. In addition, glucocorticoid has a direct effect on the olfactory mucosa itself. A previous study found that there were glucocorticoid receptors in the olfactory mucosa (45). Glucocorticoid directly induces basal cell proliferation and formation of new ORNs that replace the aged and deactivated ORNs (46). Glucocorticoid also upregulates the expression of cyclic nucleotide-gated channel protein mRNA, strengthens the adenylate cyclase and cyclic adenosine monophosphate pathway in the process of olfactory signal transduction and promotes the olfactory signal transduction, thereby improving the olfactory function (47).

The present study selects budesonide and the betamethasone compound as two different routes of administration of corticosteroids. The results reveal that after 1 week of glucocorticoid intervention by budesonide or betamethasone compound in the AR model of mice with olfactory dysfunction, the number of ORNs in the olfactory mucosa had increased, reaching levels that were comparable to the control group. However, observation of mice in the medicine-free group demonstrated that the number of ORNs in the olfactory mucosa is not significantly increased. These results demonstrated that the application of glucocorticoid has an explicit intervention effect for olfactory disorder in AR. Glucocorticoid effectively improves the number of ORNs in the olfactory mucosa and demonstrates protective effects on it. After 2 weeks of medicine intervention, the number of ORNs is not significantly changed in the two groups of different routes of medicine administration. This result reveals that the treatment effects of the two different routes of administration of glucocorticoid on olfactory dysfunction in AR can be maintained for a considerable amount of time. Intranasal local glucocorticoid, including budesonide, is not easily absorbed into the blood of the nasal mucosa; therefore, the incidence of systemic adverse reactions is low. Thus, intranasal application of local glucocorticoid is expected to be an ideal treatment method for olfactory dysfunction in AR. In conclusion, AR is an important factor causing olfactory dysfunction. Moreover, glucocorticoid alleviates olfactory dysfunction by acting on ORNs in the olfactory mucosa. In the future, further studies should be focused on how glucocorticoid activates the glucocorticoid receptors as well as the targeting mechanism in the olfactory system.

\section{Acknowledgements}

The present study was supported by the Chinese Academy of Medical Science and Peking Union Medical College.

\section{References}

1. Ni DF: Olfactory disorders and olfactory function test. Lin Chuang Er Bi Yan Hou Ke Za Zhi 17: 571-575, 2003 (In Chinese).

2. Stenner M, Vent J, Huttenbrink KB, Hummel T and Damm M: Topical therapy in anosmia: Relevance of steroid-responsiveness. Laryngoscope 18: 1681-1686, 2008.

3. Bousquet J, Khaltaev N, Cruz AA, Denburg J, Fokkens WJ, Togias A, Zuberbier T, Baena-Cagnani CE, Canonica GW, van Weel $\mathrm{C}$, et al: Allergic rhinitis and its impact on asthma (ARIA) 2008 update (in collaboration with the world health organization, GA(2)LEN and AllerGen). Allergy 86 (Suppl 63): 86-160, 2008.

4. Guilemany JM, García-Piñero A, Alobid I, Cardelús S, Centellas S, Bartra J, Valero A, Picado C and Mullol J: Persistent allergic rhinitis has a moderate impact on the sense of smell, depending on both nasal congestion and inflammation. Laryngoscope 119: 233-238, 2009.

5. Gu ZY: Respiratory tract inflammation. Zhonghua Er Bi Yan Hou Ke Za Zhi 36: 397-399, 2001 (In Chinese).

6. Amit A, Saxena VS, Pratibha N, D'Souza P, Bagchi M, Bagchi D and Stohs SJ: Mast cell stabilization, lipoxygenase inhibition, hyaluronidase inhibition, antihistaminic and antispasmodic activities of Aller-7, a novel botanical formulation for allergic rhinitis. Drugs Exp Clin Res 29: 107-115, 2003.

7. Mott AE, Cain WS, Lafreniere D, Leonard G, Gent JF and Frank ME: Topical corticosteroid treatment of anosmia associated with nasal and sinus disease. Arch Otolaryngol Head Neck Surg 123: 367-372, 1997.

8. Simola M and Malmberg H: Sense of smell in allergic and nonallergic rhinitis. Allergy 53: 190-194, 1998.

9. Kirtsreesakul V and Naclerio RM: Role of allergy in rhinosinusitis. Curr Opin Allergy Clin Immunol 4: 17-23, 2004.

10. Moll B, Klimek L, Eggers G and Mann W: Comparison of olfactory function in patients with seasonal and perennial allergic rhinitis. Allergy 53: 297-301, 1998

11. Cowart BJ, Flynn-Rodden K, McGeady SJ and Lowry LD: Hyposmia in allergic rhinitis. J Allergy Clin Immunol 91: 747-751, 1993.

12. Rombaux P, Collet S, Eloy P, Ledeghen S and Bertrand B: Smell disorders in ENT clinic. B-ENT 1 (Suppl 1): 97-109, 2005.

13. Doty RL and Mishra A: Olfactory and its alteration by nasal obstruction, rhinitis, and rhinosinusitis. Laryngoscope 111: 409-423, 2001

14. Guss J, Doghramji L, Reger C and Chiu AG: Olfactory dysfunction in allergic rhinitis. ORL J Otorhinolaryngol Relat Spec 71: 268-272, 2009.

15. van Beek TA and Montoro P: Chemical analysis and quality control of Ginkgo biloba leaves, extracts, and phytopharmaceuticals. J Chromatogr A 1216: 2002-2032, 2009.

16. Berghard A, Buck LB and Liman ER: Evidence for distinct signaling mechanisms in two mammalian olfactory sense organ. Proc Natl Acad Sci USA 93: 2365-2369, 1996.

17. Buck LB: The molecular architecture of odor and pheromone sensing in mammals. Cell 100: 611-618, 2000.

18. Kass MD, Moberly AH, Rosenthal MC, Guang SA and McGann JP: Odor-specific, olfactory marker protein-mediated sparsening of primary olfactory input to the brain after odor exposure. J Neurosci 33: 6594-6602, 2013. 
19. Lee AC, He J and Ma M: Olfactory marker protein is critical for functional maturation of olfactory sensory neurons and development of mother preference. J Neurosci 31: 2974-2982, 2011.

20. Faulcon P, Biacabe B and Bonfils P: Contribution of corticosteroid treatment in neurosensorial anosomia: A series of 62 patients. Ann Otolaryngol Chir Cervicofac 117: 374-377, 2000 (In French).

21. Heilmann S, Huettenbrink KB and Hummel T: Local and systemic administration of corticosteroid in the treatment of olfactory loss. Am J Rhinol 18: 29-33, 2004.

22. Stevens MH: Steroid-dependent anosmia. Laryngoscope 111: 200-203, 2001

23. Hilberg O: Effect of terfenadine and budesonide on nasal symptoms, olfaction, and nasal airway patency following allergen challenge. Allergy 50: 683-688, 1995.

24. Guan J, Ni DF, Wang J, Zhu Y, Xu C, Chen X and Liu J: Therapy for olfactory disorder associated with URTI along with nasal and accessory nasal diseases. Lin Chung Er Bi Yan Hou Tou Jing Wai Ke Za Zhi 24: 484-488, 2010 (In Chinese).

25. Miescher SM and Vogel M: Molecular aspects of allergy. Mol Aspects Med 23: 413-462, 2002.

26. Takahashi N, Aramaki Y and Tsuchiy S: Allergic rhinitis model with Brown Norway rat and evaluation of antiallergic drugs. J Pharmacobiodyn 13: 414-420, 1990.

27. Nakaya M, Dohi M, Okunishi K, Nakagome K, Tanaka R, Imamura M, Baba S, Takeuchi N, Yamamoto $\mathrm{K}$ and Kaga $\mathrm{K}$ : Noninvasive system for evaluating allergen-induced nasal hypersensitivity in murine allergic rhinitis. Lab Invest 86: 917-926, 2006.

28. Tanaka K, Okamoto Y, Nagaya Y, Nishimura F, Takeoka A, Hanada S, Kohno S and Kawai M: A nasal allergy model developed in the guinea pig by application of 2,4-toluene diisocyanate. Int Arch Allergy Appl Immunol 85: 392-397, 1988.

29. Sehmi R, Wood LJ, Watson R, Foley R, Hamid Q, O'Byrne PM and Denburg JA: Allergen-induced increases in IL-5 receptor alpha-subunit expression on bone marrow-derived CD34+ cells from asthmatic subjects. A novel marker of progenitor cell commitment towards eosinophilic differentiation. J Clin Invest 100: 2466-2475, 1997.

30. Lin J, Wei YX, Wang XD and Yang L: Observation of the olfactory mucosa in mice with allergic rhinitis olfactory dysfunction. Zhongguo Er Bi Yan Hou Tou Jing Wai Ke 15: 465-468, 2008 (In Chinese).

31. Carr VM, Robinson AM and Kern RC: Tissue-specific effects of allergic rhinitis in mouse nasal epithelia. Chem Senses 37: 655-668, 2012.

32. Wirth S, Stemmelin J, Will B, Christen YVES and Di Scala G: Facilitative effects of EGb 761 on olfactory recognition in young and aged rats. Pharmacol Biochem Behav 65: 321-326, 2000.

33. Nathan BP, Yost J, Litherland MT, Struble RG and Switzer PV: Olfactory function in apoE knockout mice. Behav Brain Res 150 $1-7,2004$.
34. Liebenauer LL and Slotnick BM: Social organization and aggression in a group of olfactory bulbectomized male mice. Physiol Behav 60: 403-409, 1996.

35. Seiden AM and Duncan HJ: The diagnosis of a conductive olfactory loss. Laryngoscope 111: 9-14, 2001.

36. Klimek L and Eggers G: Olfactory dysfunction in allergic rhinitis is related to nasal eosinophilic inflammation. J Allergy Clin Immunol 100: 158-164, 1997.

37. Doty RL and Mishra A: Olfaction and its alternation by nasal obstruction, rhinitis, and rhinosinusitis. Laryngoscope 111: 409-423, 2001

38. Chen ZH and Ni DF: Research progress of odorant receptor. Guo Ji Er Bi Yan Hou Tou Jing Wai Ke Za Zhi 15: 465-468, 2008. (In Chinese).

39. Hummel T, Rissom K, Reden J, Hähner A, Weidenbecher M and Hüttenbrink KB: Effects of olfactory training in patients with olfactory loss. Laryngoscope 119: 496-499, 2009.

40. Henkin RI, Potolicchio SJ Jr and Levy LM: Improvement in smell and taste dysfunction after repetitive transcranial magnetic stimulation. Am J Otolarnygol 32: 38-46, 2011.

41. Hotchkiss WT: Influence of prednisone on nasal polyposis with anosmia; preliminary report. AMA Arch Otolaryngol 64: 478-479, 1956.

42. Fukazawa K, Fujii M, Tomofuji S, Ogasawara H, Seo W and Sakagami M: Local injection of dexamethasone acetate suspension into the nasal mucosa in cases of olfactory disturbance. Nippon Jibinkoka Gakkai Kaiho 102: 1175-1183, 1999 (In Japanese)

43. Seo BS, Lee HJ, Mo JH, Lee CH, Rhee CS and Kim JW: Treatment of postviral olfactory loss with glucocorticoids, Ginkgo biloba, and mometasone nasal spray. Arch Otolaryngol Head Neck Surg 135: 1000-1004, 2009.

44. Lee GS, Cho JH, Park CS, Jung SH, Lee DH, Jun BC, Song CE and Cho KJ: The effect of Ginkgo biloba on the expression of intermediate-early antigen (c-fos) in the experimentally induced anosmic mouse. Auris Nasus Larynx 36: 287-291, 2009.

45. Robinson AM, Kern RC, Foster JD, Fong KJ and Pitovski DZ: Expression of glucocorticoid receptor mRNA and protein in the olfactory mucosa: Physiologic and pathophysiologic implications. Laryngoscope 108: 1238-1242, 1998.

46. Takanosawa M,Nishino H,Ohta Y and Ichimura K: Glucocorticoids enhance regeneration of murine olfactory epithelium. Acta Otolaryngol 129: 1002-1009, 2009.

47. Wei Y, Zhang C, Miao X, Xing F, Liu X, Zhao H, Zhan X and Han D: Effects of glucocorticoid on cyclic nucleotide-gated channels of olfactory receptor neurons. J Otolaryngol Head Neck Surg 38: 90-95, 2009. 